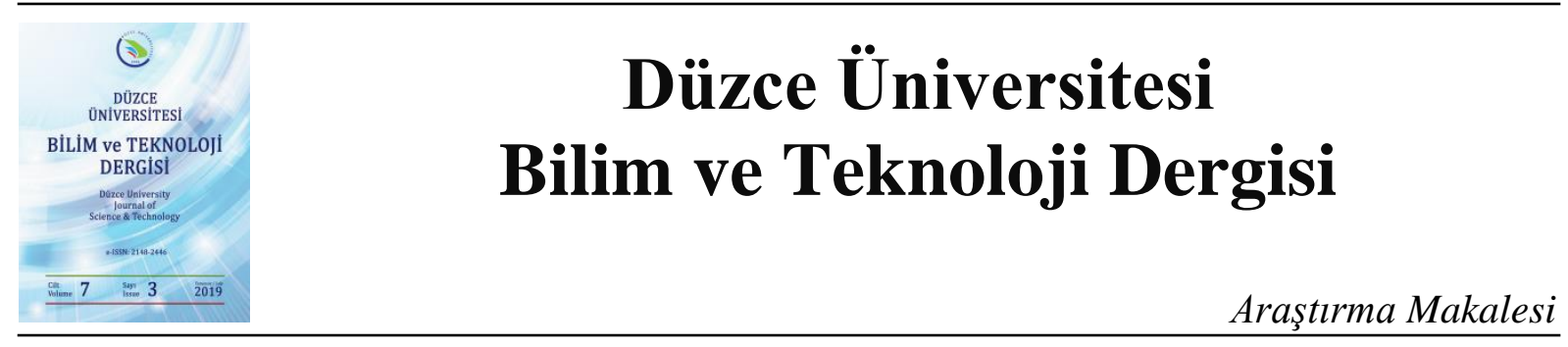

\title{
ÇBAG Tabanlı Rüzgâr Santralinde DGİY için Simetrik ve Asimetrik Arızaların Analizi
}

(iD) M. Kenan DÖŞOĞLU, ${ }^{\mathrm{a}, *}$

${ }^{a}$ Elektrik Elektronik Bölümü, Teknoloji Fakültesi, Düzce Üniversitesi, Düzce, TÜRKIYE

* Sorumlu yazarin e-posta adresi: kenandosoglu@duzce.edu.tr

DOI : 10.29130/dubited.528531

\begin{abstract}
ÖZET
Şebeke bağlantılı rüzgar santrali güç sistemi tarafında oluşan çeşitli gerilim düşmelerinden etkilenmektedir. Özellikle simetrik ve asimetrik arızalarda rüzgar santralinin şebeke bağlantı kriterlerinin belirlenmesi önemli bir konudur. Bu çalışmada, 2.3 MVA gücündeki ÇBAG tabanlı rüzgar santralinin Düşük Gerilim İyileştirme Yeteneği (DGIY) için simetrik ve asimetrik arızalar karşısındaki durumları incelenmiştir. Simetrik arıza olarak 3 faz arıza ve 3 faz toprak arızası kullanılırken, Asimetrik arızalar için 2 faz arızası ve 2 faz toprak arızası kullanılmıştır. Şebeke tarafında meydana gelen arızalar esnasında $34.5 \mathrm{kV}$ bara gerilimi ÇBAG çıkış gerilimi, açısal hızı, elektriksel momenti, d-q eksen akım değişimleri incelenmiş̧ir. 3 faz arıza, 3 faz toprak, 2 faz arıza ve 2 faz toprak arızasında elde edilen sonuçlar karşılaştırılmış ve yorumlanmıştır. Elde edilen sonuçlarda 3 faz arıza analizinde $34.5 \mathrm{kV}$ 'luk bara gerilimi ve ÇBAG parametrelerinin diğer arızalara nazaran daha çok etkilenmiştir.
\end{abstract}

Anahtar Kelimeler: ÇBAG tabanlı rüzgar santrali, Şebeke bağlantı kriteri, Simetrik ve asimetrik arızalar, DGIYY

\section{Analysis of Symmetrical and Unsymmetrical Faults for LVRT Capability in DFIG Based Wind Farm}

\begin{abstract}
The grid-connected wind farm is affected by various voltage drops occurrred in the power system side. Especially in symmetric and asymmetric faults, the determination of grid connection criteria of the wind farm is an important issue. In this study, the situation of the 2.3 MVA power DFIG based wind farm against symmetrical and asymmetric faults for Low Voltage Ride Through (LVRT) capability was investigated. While 3 phase fault and 3 phase fault ground are used as symmetric fault, 2 phase fault and 2 phase ground fault are used for asymmetric faults. $34.5 \mathrm{kV}$ bus voltage, angular speed, electrical moment, d-q axis stator current variations were investigated during faults occurring on the grid side. The results obtained in 3 phase fault, 3 phase ground, 2 phase fault and 2 phase ground fault are compared and interpreted. In the results obtained, it was seen that 34.5 $\mathrm{kV}$ bus voltage and DFIG parameters in 3 phase fault analysis were affected more than other faults.
\end{abstract}

Keywords: DFIG based wind farm, Grid connect criteria, Symmetrical and unsymmetrical faults, LVRT

Geliş: 18/02/2019, Düzeltme: 07/03/2019, Kabul: 19/03/2019 


\section{$\underline{\text { I. GiRis }}$}

on yıllarda fosil yakıt rezervindeki azalmalar ve fiyatının yüksek olmasından dolayı yenilenebilir enerji kaynaklarına yönelmeler başlamıştır. Yenilenebilir enerji kaynaklarının en popüler olanlarından biriside rüzgar enerjisidir. Rüzgar enerjisinden elektrik enerjisi dönüşümünde rüzgar santralinde generatör kullanılmaktadır. Özellikle Çift Beslemeli Asenkron Generatör (ÇBAG) güç ve moment kontrolünün iyi olmasından dolayı yaygın bir şekilde tercih edilmektedir. Şebekeye bağlı olarak çalışan ÇBAG tabanlı rüzgar santralleri bazı olumsuz durumlar ile karşı karşıya kalmaktadır. Literatürde bunlar ile ilgili çalışmalar mevcuttur. Rüzgar hızının düşük olması ve yüksek olması esnasında koruma tertibatı ÇBAG tabanlı rüzgar santralini şebekeden ayırmaktadır. Şebekeye bağlanma ve şebekeden ayrılma esnasında büyük ani akımları meydana gelmektedir [1,2]. Büyük ani akımların meydana gelmesine neden olan olaylardan biriside asenkron motorların belli bir zaman içerisinde devreye girip çıkmasıdır. Asenkron motorların devreye girip çıkmasında zamana bağlı olarak gerilimde düşme, akımlarda yükselme ve tüm gözetlenen parametre değerlerinde salınımların oluştuğu görülmektedir [3,4]. Asenkron motorların yanısıra diğer lineer olmayan yük modellerinde ÇBAG tabanlı rüzgar santrali üzerinde belirgin etkileri olduğunu söyleyebiliriz. Farklı aktif ve reaktif güç değerlerinde baraların çalışma limitlerinin değiştiği ilgili çalışmalarda gözlemlenmiştir $[5,6]$. Şebeke bağlantılı ÇBAG tabanlı rüzgar santralinde güç elektroniği tabanlı yükler sistem gerilim ve akımlarını bozmaktadır. Güç kalitesinde harmonik denilen saf sinüs akım ve gerilimlerdeki bozulmaların sistem üzerinde oluşturmuş olduğu etkiler incelenmiştir [7]. Şebeke tarafında oluşan olumsuz durumlardan biriside kısa devre gücü ve $\mathrm{X} / \mathrm{R}$ oranıdır. Şebeke bağlantılı ÇBAG tabanlı rüzgar santralinde farklı kısa devre gücü ve $\mathrm{X} / \mathrm{R}$ oranlarının etkisi incelenmiştir. Sonsuz şebekedeki kısa devre gücü ve $\mathrm{X} / \mathrm{R}$ oranının gerilim düşmesinde oldukça etkili olduğu ilgili çalışmalarda görülmüştür [8,9]. Sonsuz makinalı ve çok makinalı güç sistemine entegre edilen ÇBAG tabanlı rüzgar santralinde geçici kararlılık analizinde kesicilerin yanlış koordinasyonu sonucu açması veya hat kopması olayı incelenmiştir. Kesici açması ve hat kopması olaylarında zamana bağlı olarak sistem üzerinde ne gibi etkilerin olduğu incelenmiştir [10,11]. Şebekeye bağlı rüzgar santralinde çeşitli arıza analizleri incelenmiştir. Baralarda meydana gelen arızaların sistem üzerinde oluşturmuş olduğu etkiler kapsamlı olarak irdelenmiştir [12,13].

Yapılan bu çalışmada hatlarda meydana gelen simetrik ve asimetrik arızaların ÇBAG tabanlı rüzgar santralindeki DGIY üzerindeki etkileri incelenmiştir. Rüzgar santralinin şebeke bağlantılı kriterlerine bağl1 olarak gerilim düşmelerinin etkilerinin neler olduğu görülmüştür. Özellikle de Türkiye'deki rüzgar santral gücü, gerilim seviyeleri ve düşürücü transformatör güçlerine bağlı olarak düşük gerilim iyileştirme yeteneği açısından değerlendirmeler yapılmışıı. Yapılan bu çalışmada simetrik arıza olarak kullanılan 3 faz arızasının asimetrik arızalar olarak kullanılan 2 faz ve faz-toprak arızasına nazaran gerilim profilini çok azalttığını ve şebeke bağlantı kriterini karşılamadığı görülmüştür.

\section{II. ÇIFT Beslemeli Asenkron Generatör (CBAG) TABAnli RÜZGAR}

\section{$\underline{\text { SANTRALI }}$}

ÇBAG dişli kutusu, crowbar ünitesi, generatör ve şebeke-rotor evirici devresinden oluşmaktadır. ÇBAG’ün dever modeli Şekil 1'de gösterilmiştir. 


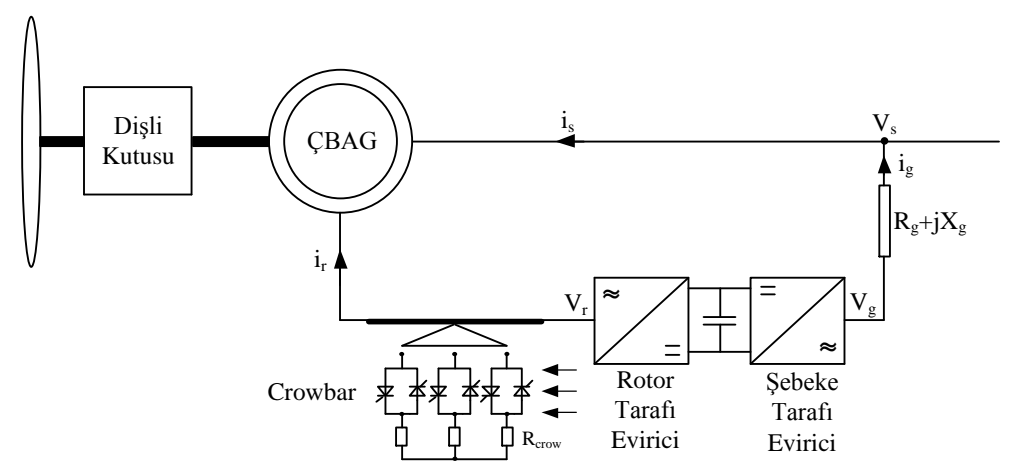

Şekil 1. ÇBAG devre modeli

ÇBAG stator kısmı direk olarak şebekeye bağlanırken, rotor kısmı arka arkaya bağlı evirici devresi sayesinde şebekeye bağlanmaktadır. Arka arkaya bağlı evirici devresi ÇBAG'nin farklı hızlarda çalışmasına müsade etmektedir. ÇBAG rüzgar hızının düşük ve yüksek olduğu durumlarda belli bir seviyeye kadar çıkış gücünü sabit tutma özelliğine sahiptir. Rotor tarafındaki evirici devresinde bulunan crowbar ünitesi seviye sınırlarının ihmal edilmesi durumunda generatörü şebekeden ayırmaktadır. Rotor tarafı ve şebeke tarafı evirici devresi kontrol eşitlikleri denklem 1 ile denklem 14 arasında gösterilmiştir.

$$
\begin{aligned}
& \frac{d x_{1}}{d t}=P_{r e f}+P_{s} \\
& i_{q r_{-} r e f}=K_{p 1}\left(P_{r e f}+P_{s}\right)+K_{i 1} x_{1} \\
& \frac{d x_{2}}{d t}=i_{q r_{-} r e f}-i_{q r}=K_{p 1}\left(P_{r e f}+P_{s}\right)+K_{i 1} x_{1}-i_{q r} \\
& \frac{d x_{3}}{d t}=v_{s_{-} r e f}-v_{s} \\
& i_{d r_{-} r e f}=K_{p 3}\left(v_{s_{-} r e f}-v_{s}\right)+K_{i 3} x_{3} \\
& \frac{d x_{4}}{d t}=i_{d r_{-} r e f}-i_{d r}=K_{p 3}\left(v_{s_{-} r e f}-v_{s}\right)+K_{i 3} x_{3}-i_{d r} \\
& v_{q r}=K_{p 2}\left(K_{p 1} \Delta P+K_{i 1} x_{1}-i_{q r}\right)+K_{i 2} x_{2}+s w_{s} L_{m} i_{d s}+s w_{s} L_{r r} i_{q r} \\
& v_{d r}=K_{p 2}\left(K_{p 3} \Delta v+K_{i 3} x_{3}-i_{d r}\right)+K_{i 2} x_{4}-s w_{s} L_{m} i_{q s}-s w_{s} L_{r r} i_{d r} \\
& \frac{d x_{5}}{d t}=V_{d c_{-} r e f}-V_{d c}
\end{aligned}
$$




$$
\begin{aligned}
& i_{d g r i d_{-} \text {ref }}=-K_{p d g r i d} \Delta v_{d c}+K_{1 d g r i d} x_{5} \\
& \frac{d x_{6}}{d t}=i_{d g r i d}{ }_{-r e f}-i_{d g r i d}=-K_{p d g r i d} \Delta v_{d c}+K_{1 d g r i d} x_{5}-i_{d g r i d} \\
& \frac{d x_{7}}{d t}=i_{q g \text { rid }-r e f}-i_{q g r i d} \\
& \Delta v_{d g r i d}=K_{p g r i d} \frac{d x_{6}}{d t}+K_{i g r i d} x_{6}=K_{p g r i d}\left(-K_{p d g r i d} \Delta v_{d c}+K_{1 d g r i d} x_{5}-i_{d g r i d}\right)+K_{1 \text { grid }} x_{6} \\
& \Delta v_{q g \text { rid }}=K_{p g r i d} \frac{d x_{7}}{d t}+K_{i g r i d} x_{7}=K_{p g \text { rid }}\left(i_{q g \text { rid_ref }}-i_{q g \text { rid }}\right)+K_{1 \text { grid }} x_{7}
\end{aligned}
$$

Burada, $\mathrm{x}_{1}, \mathrm{x}_{2}, \mathrm{x}_{3}, \mathrm{x}_{4}$ rotor tarafındaki evirici kontrol eşitlikleri, $\mathrm{K}_{\mathrm{p} 1}$ ve $\mathrm{K}_{\mathrm{i} 1}$ güç düzenleyici oransal ve integral oranlar1, $K_{p 2}$ ve $K_{i 2}$, rotor tarafındaki eviricinin oransal ve integral oranları, $K_{p 3}$ ve $K_{i 3}$, şebeke gerilim düzenleyicisinin oransal ve integral oranları, $i_{\text {dr_ref }} v e i_{\text {qr_ref }}$ rotor tarafindaki eviricinin $d-q$ ekseni için akım kontrol referansı,$v_{\mathrm{s}}$ ve $\mathrm{v}_{\mathrm{s}_{-} \text {ref }}$, özel çıkış gerilimi ve özel referans gerilimi, $\mathrm{P}_{\mathrm{s}}$ ve $\mathrm{P}_{\text {ref }}$ aktif güç ve aktif güç referans değeri, $s$ kayma, $w_{s}$ statorun açısal hızı, $\mathrm{L}_{\mathrm{m}}$ manyetik endüktans $\mathrm{L}_{\mathrm{rr}}$, rotor ve manyetik endüktansın toplamı, $\Delta \mathrm{v}$ ve $\Delta \mathrm{P}$ gerilim ve aktif güç değişim değeri, $\mathrm{v}_{\mathrm{dr}} \mathrm{ve} \mathrm{v}_{\mathrm{qr}}$ rotor d-q eksen gerilimi, $i_{\mathrm{ds}}, i_{\mathrm{dr}}, \mathrm{i}_{\mathrm{qs}}, \mathrm{i}_{\mathrm{qr}} \mathrm{d}-\mathrm{q}$ eksen stator ve rotor akımları $\mathrm{x}_{5}, \mathrm{x}_{6}, \mathrm{x}_{7}$ şebeke tarafındaki evirici kontrol eşitlikleri, $\mathrm{K}_{\text {pdgrid }}$ ve $\mathrm{K}_{\text {idgrid }} \mathrm{DC}$ bara gerilim düzenleyici oransal ve integral oranları, $\mathrm{K}_{\text {pgrid }}$ ve $\mathrm{K}_{\text {igrid }}$ şebeke tarafındaki eviricinin oransal ve integral oranları, $\mathrm{V}_{\mathrm{dc}}$ ve $\mathrm{V}_{\mathrm{dc} \_ \text {ref }} \mathrm{DC}$ link gerilimi ve DC link gerilim referansı, $i_{\text {dgrid }}$ ve $i_{\text {dgrid_ref }}$ şebeke tarafındaki evirici $d$ eksen elemanı ve şebeke tarafındaki evirici için kontrol referansı, $i_{\text {qgrid }}$ ve $i_{\text {qgrid_ref }}$, şebeke tarafindaki eviricinin q eksen akımı ve şebeke tarafindaki evirici için kontrol referansı, $\Delta \mathrm{v}_{\text {dgrid }}$ ve $\Delta \mathrm{v}_{\mathrm{qgrid}}$, $\mathrm{d}$-q eksen şebeke tarafi evirici gerilim değişim değeri, $\Delta \mathrm{v}_{\mathrm{dc}}$ DC link gerilim değişim değeridir [14]. ÇBAG’ün stator ve rotor devresi matematiksel modellemesinde hızlı ve doğru hesaplama yapabilmesi için d-q eksen stator ve rotor gerilimleri kullanılmaktadır. D-q eksen stator ve rotor gerilimleri denklem 15 ve denklem 18 arasında gösterilmiştir.

$$
\begin{aligned}
& v_{d s}=R_{s} i_{d s}+w_{s} \lambda_{q s}+\frac{d}{d t} \lambda_{d s} \\
& v_{q s}=R_{s} i_{q s}-w_{s} \lambda_{d s}+\frac{d}{d t} \lambda_{q s} \\
& v_{d r}=R_{r} i_{d r}-s w_{s} \lambda_{q r}+\frac{d}{d t} \lambda_{d r} \\
& v_{q r}=R_{r} i_{q r}+s w_{s} \lambda_{d r}+\frac{d}{d t} \lambda_{q r}
\end{aligned}
$$

ÇBAG stator ve rotor akı denklemleri denklem 19 ve denklem 22 arasında gösterilmiştir.

$$
\lambda_{d s}=\left(L_{s}+L_{m}\right) i_{d s}+L_{m} i_{d r}
$$




$$
\lambda_{q s}=\left(L_{s}+L_{m}\right) i_{q s}+L_{m} i_{q r}
$$

$$
\lambda_{d r}=\left(L_{r}+L_{m}\right) i_{d r}+L_{m} i_{d s}
$$

$$
\lambda_{q r}=\left(L_{r}+L_{m}\right) i_{q r}+L_{m} i_{q s}
$$

Bu eşitliklerde; $v_{d s}, v_{q s} d-q$ eksen stator gerilimleri, $d$-q stator ve rotor kaçak akıları $R_{s}$ ve $R_{r}$, $d-q$ stator ve rotor dirençleri, $\mathrm{L}_{\mathrm{s}}$ and $\mathrm{L}_{\mathrm{r}} \mathrm{d}-\mathrm{q}$ stator ve rotor endüktanstır [15-17].

\section{DÜȘÜK GERILIMI İYILEȘTIRME YETENEĞİ}

Düşük Gerilim İyileştirme Yeteneği (DGIY) şebekeye bağlı rüzgar santralinin şebekede oluşan düşük gerilime karşın belirli bir zamana kadar şebeke bağlantısından kopmadan çalışmaya devam etmesini gerekli kılmaktadır. Geçmişte herhangi bir kısa devre anında veya büyük güçlü yüklerin devreye girmesi esnasında oluşan gerilim düşümlerinde küçük güçlü rüzgar santrali şebekeden ayrilıp tekrardan şebekeye bağlanmaktaydı. Ancak günümüzde büyük güçlü olarak imal edilen rüzgar santrallerinin şebekeden ayrılması tehlikeli olmaktadır. Büyük güçlü sistemlerin şebekeden ayrılması çok makinalı güç sisteminde yük akışı dengelerinin bozulmasına ve gerilim çökmelerine sebep olmaktadır. Bu nedenle her ülkenin uluslararası şebeke kod gereksinimine uyması gerekmektedir. $\mathrm{Bu}$ nedenle, elektrik üretici tesislerin şebekeye bağlı kalmasını garanti etmek amacıyla şebeke kodu gereksinimi belirlenmiş̧ir. Dahası birçok şebeke kodu, şebekenin gerilim düşmeleri sırasında desteklenmesini talep etmektedir. Bu gereksinim DGIYY olarak bilinmektedir. Üretim tesisleri şebekeye reaktif akımı vererek destekleyebilir ve böylece gerilimi yükseltmiş olmaktadır. Arıza temizleme işleminden hemen sonra, aktif güç çıkışı, arızanın oluşmasından önceki belirli bir süre içinde tekrar eski değerine yükseltilmesi gerekmektedir. Bu gereklilik yenilenebilir enerji kaynaklarının şebeke bağlantılı çalışması istenen her yerde uygulanmaktadır.

\section{BENZETIM ÇALIȘMASI}

2,3 MW'lık şebekeye bağlı rüzgar santrali sistemi Şekil 2'de gösterilmiştir. Rüzgar santrali şebeke tarafinda meydana gelen simetrik ve asimetrik arızalardaki etkileşimini incelemek için kullanılmıştır.

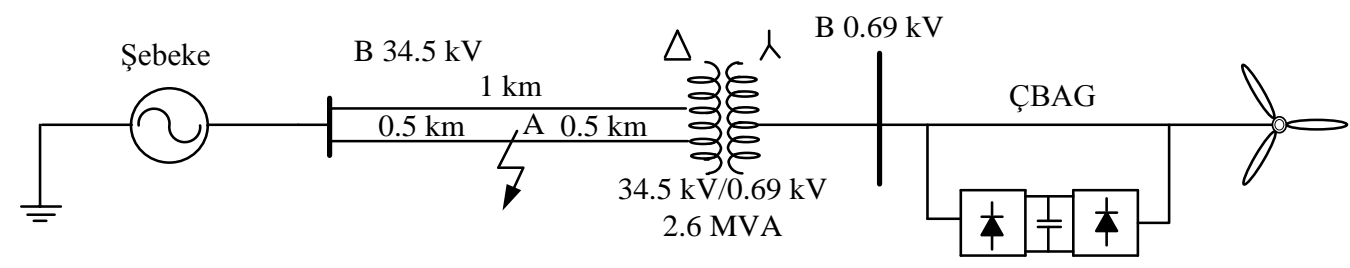

Şekil 2. Benzetim çalışması yapılan sistem

Rüzgar santrali 2.6 MW gücündeki $0.69 \mathrm{kV} / 34.5 \mathrm{kV}$ gerilim düşüren bir transformatör vasıtasıyla şebekeye bağlanmıştır. 2.6 MW gücündeki yükseltici trafo ve $2.3 \mathrm{MW}$ 'lık rüzgar santrali Türkiye'de üretimi yapılan parametrelerden oluşmaktadır. $34.5 \mathrm{kV}$ 'luk şebeke ile rüzgar santrali arasında $1 \mathrm{~km}$ 'lik mesafe bulunmaktadır. İletim hattı parallel 2 hattan oluşmaktadır. Rüzgar hızı bu sistemde $8 \mathrm{~m} / \mathrm{s}$ 
olarak sabit düşünülmüştür. Transformatörün doyumu dikkate alınmamıştır. 34.5 kV'luk şebekenin kısa devre gücü $2500 \mathrm{MVA}$ ve X/R oran 7 seçilmiştir. ÇBAG tabanlı rüzgar santralinin stator direnci $0.00706 \mathrm{ohm}$, rotor direnci $0.005 \mathrm{ohm}$, stator endüktans 0.171 Henry, rotor endüktans 0.156 Henry ve eylemsiz momenti 3.5 olarak seçilmiştir [19].

\section{BENZETIM ÇALIȘMASI SONUÇLARI}

Benzetim çalışması yapılan sistemde arıza iletim hattının ortasında meydana gelmektedir. Arıza 0.6 saniyede başlayıp 0.65 saniyede sona ermektedir. İlk senaryo ve ikinci senaryoda 3 faz arızası ve 3 faz toprak arızası dikkate alınmıştır. 3 faz ve 2 faz arıza sonucunda $34.5 \mathrm{kV}$ bara gerilimi, ÇBAG çıkış gerilimi, elektriksel moment ve d-q eksen stator akımlarındaki değişimler Şekil 3 ile Şekil 8 arasında gösterilmiştir.

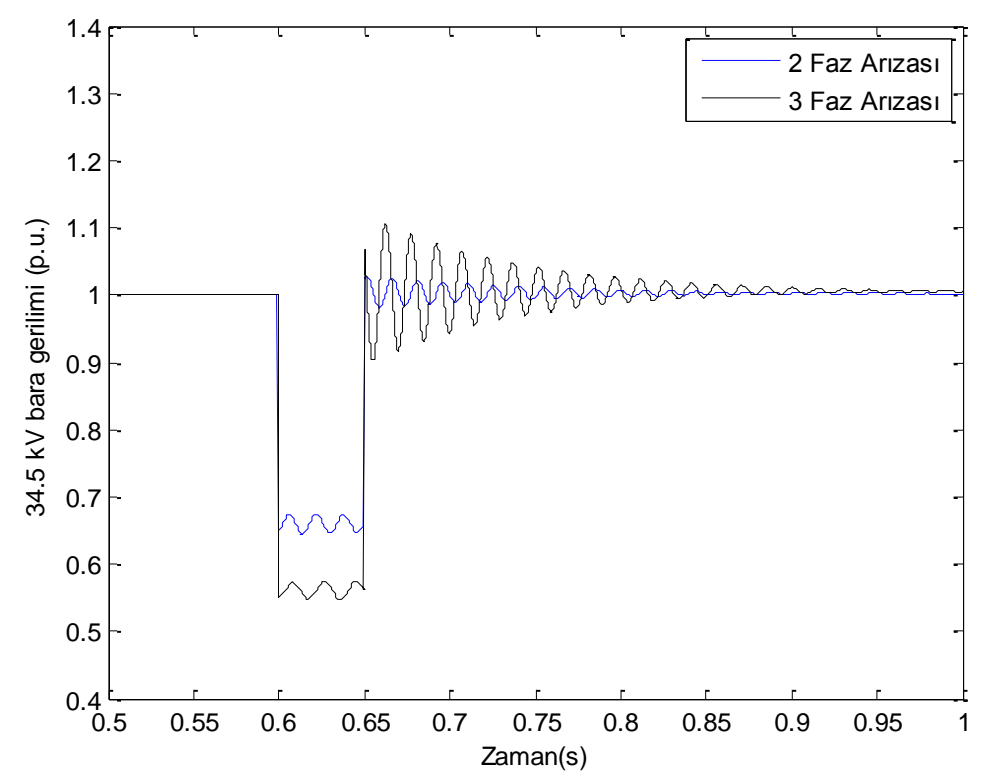

Şekil 3. 3 faz ve 2 faz arıasinda $34.5 \mathrm{kV}$ bara gerilimi

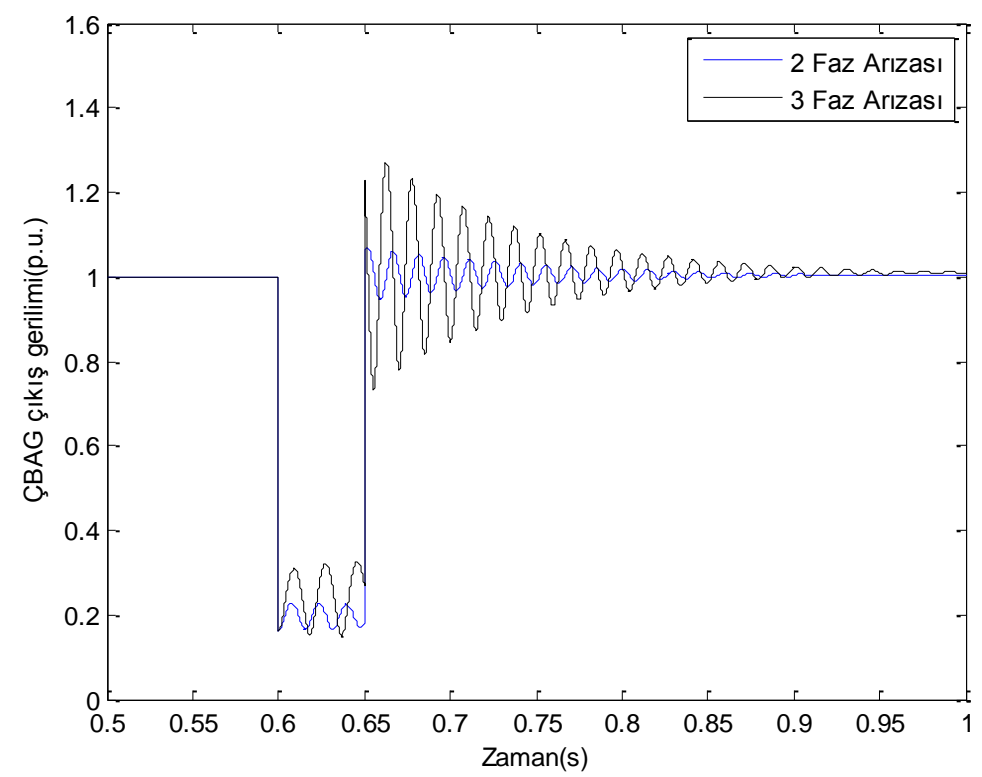


Şekil 4. 3 faz ve 2 faz arızasında ÇBAG çıkış gerilimi

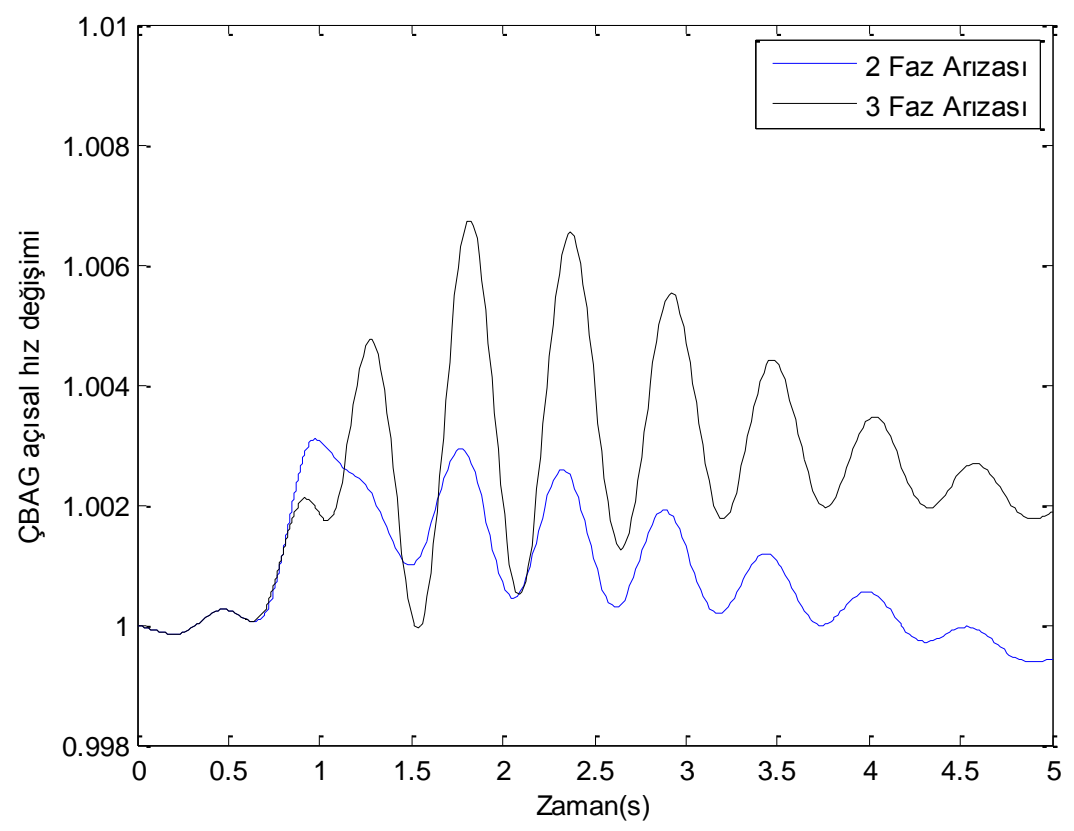

Şekil 5. 3 faz ve 2 faz arızasında ÇBAG açısal hız değişimi

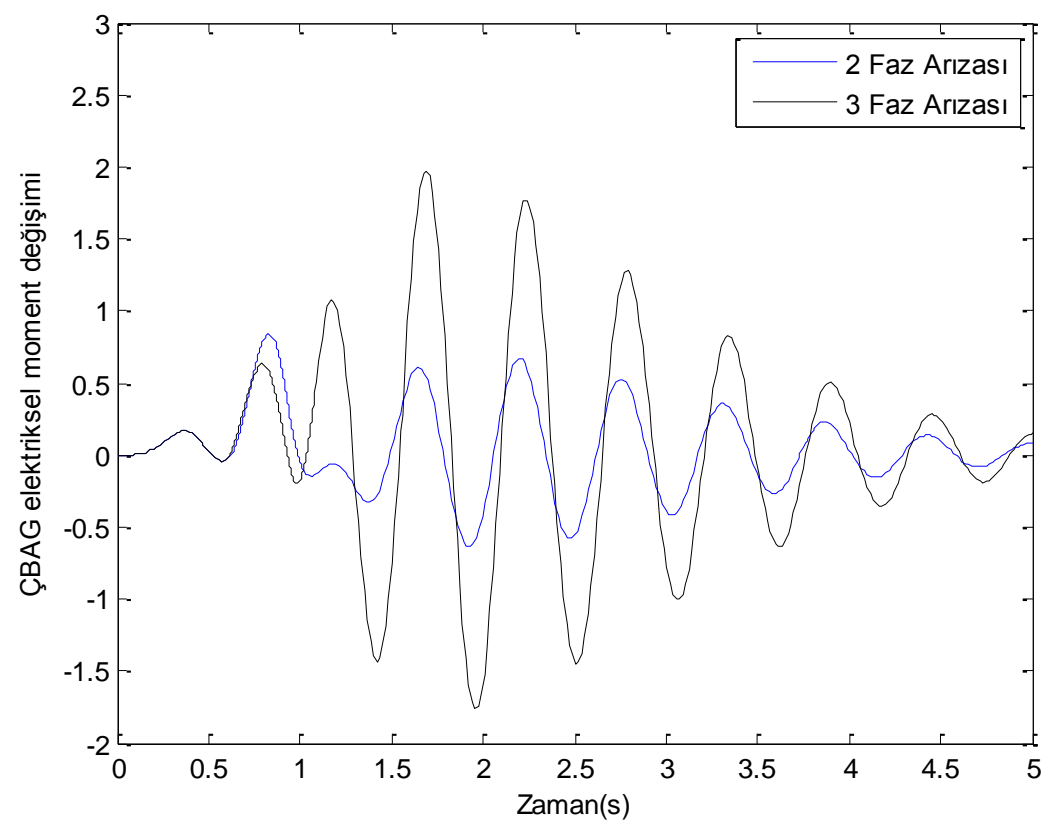

Şekil 6. 3 faz ve 2 faz arızasında ÇBAG elektriksel moment değişimi 


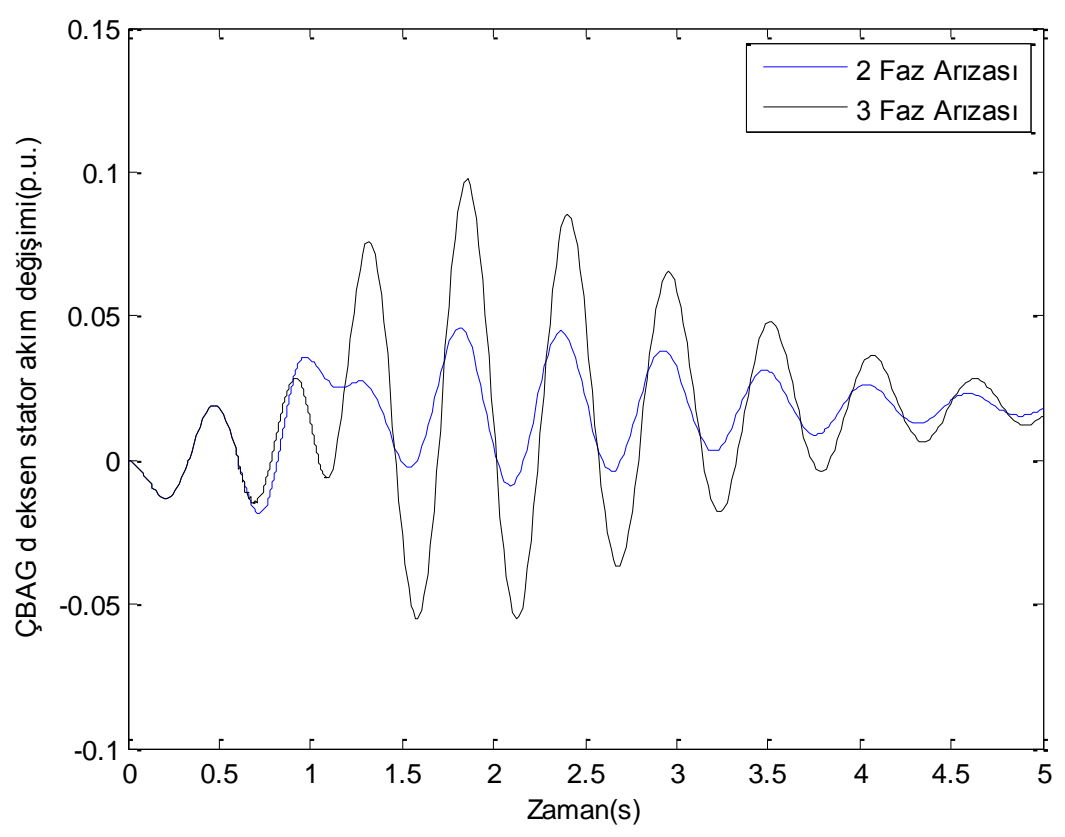

Şekil 7. 3 faz ve 2 faz arızasında ÇBAG d eksen stator akım değişimi

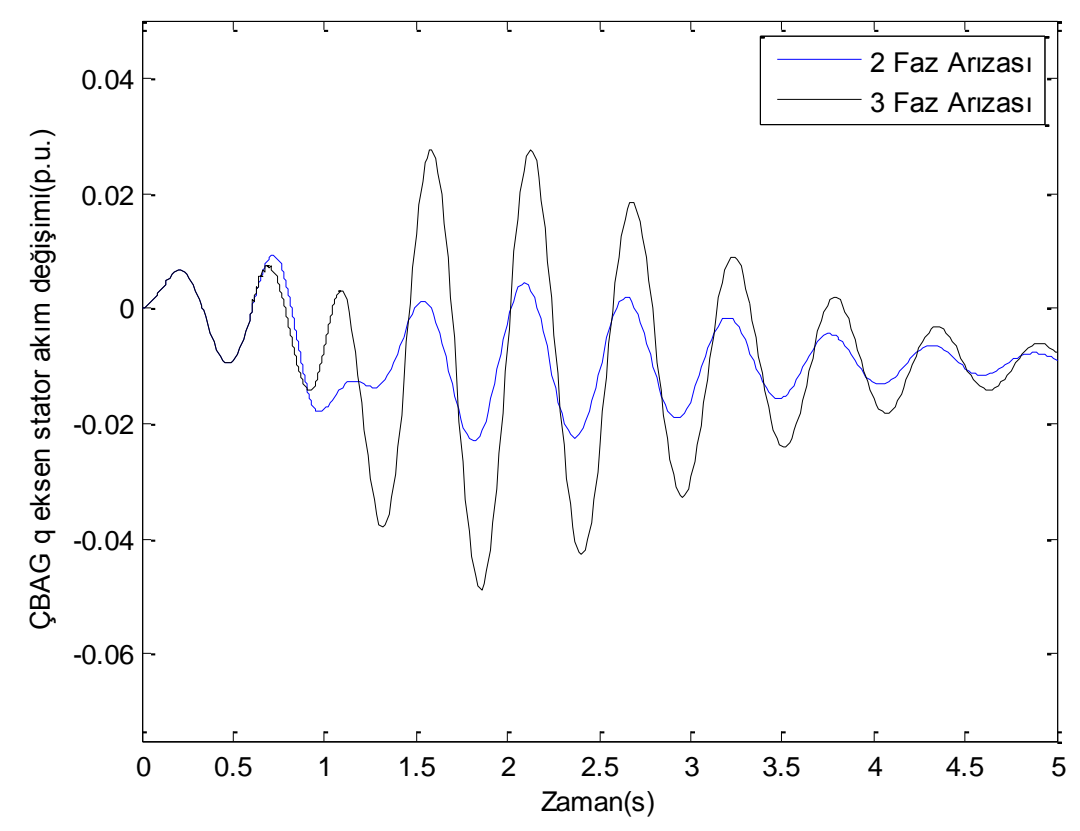

Şekil 8. 3 faz ve 2 faz arızasında ÇBAG q eksen stator akım değişimi

3 faz arıza esnasında $34 . \mathrm{kV}$ bara gerilimi 0.55 p.u. değerinde, ÇBAG çıkış geriliminin 0.2 p.u. civarına düştüğü görülmektedir. $2 \mathrm{faz}$ arıza esnasında ise $34.5 \mathrm{kV}$ bara gerilimi 0.65 p.u., ÇBAG çıkış geriliminin 0.2 p.u civarında olduğu görülmüştür. 3 faz arıza sonrasında $34.5 \mathrm{kV}$ bara gerilimi ve ÇBAG çıkış geriliminin 0.3 saniyede kararlı hale geldiği görülmektedir. 2 faz arıza sonrasında 34.5 $\mathrm{kV}$ bara gerilimi ve ÇBAG çıkış geriliminin 0.22 saniye sonra kararlı hale geldiği görülmektedir. Açısal hız değişiminde açısal hızın 3 faz arıza esnasında 1.007 p.u. değerine kadar yükseldiği görülürken, 2 faz arızada açısal hızın yaklaşık olarak 1.025 p.u. değerine yükseldiği görülmüştür. 3 faz arızada elektriksel moment ve d-q eksen stator akım değişimlerinin sırasıyla arıza sonrasında 5 saniyede kararlı hale geldiği görülmüştür. İkinci senaryoda $34.5 \mathrm{kV}$ 'luk barada 3 faz toprak arızası ve 2 
faz toprak arızası meydana gelmektedir. Arıza süresi 0.6 saniye ile 0.65 saniye arasında olmaktadır.3 faz toprak ve 2 faz toprak arızası analizinde $34 . \mathrm{kV}$ bara gerilimi, ÇBAG çıkış gerilimi, ÇBAG açısal hız değişimi, ÇBAG elektriksel moment değişimi ve d-q eksen stator akım değişimleri Şekil 9 ile Şekil 14 arasında gösterilmiştir.

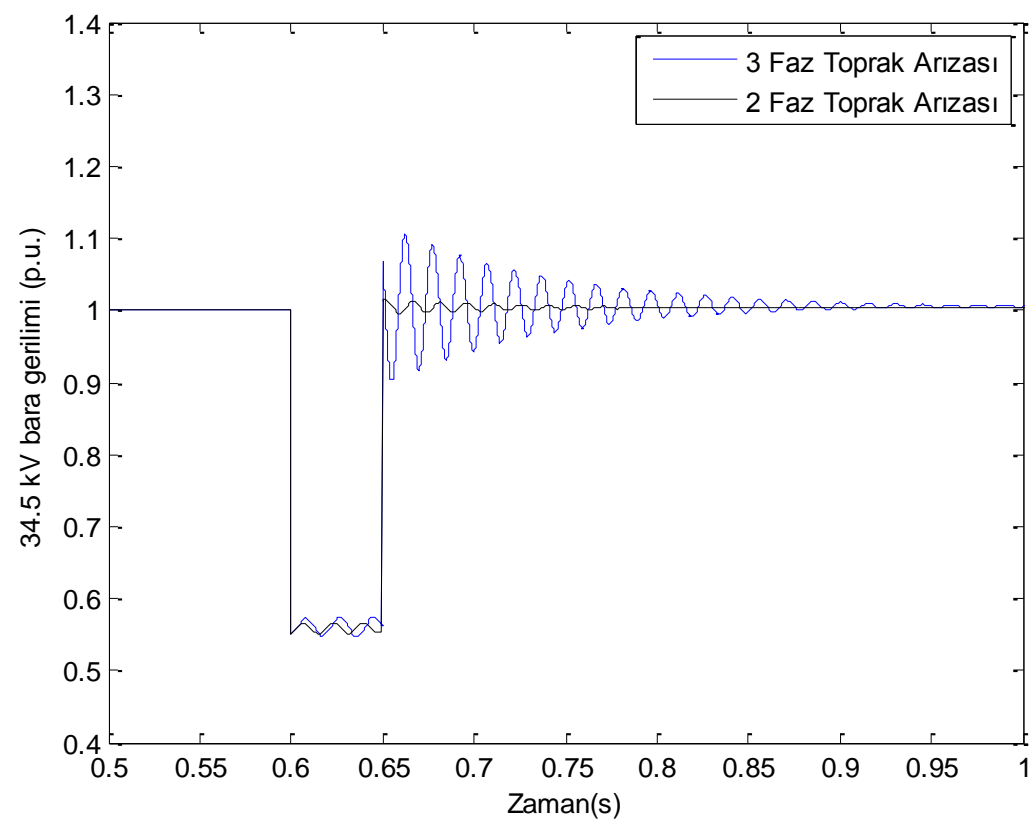

Şekil 9. 3 faz toprak ve 2 faz toprak arıasinda $34.5 \mathrm{kV}$ bara gerilimi

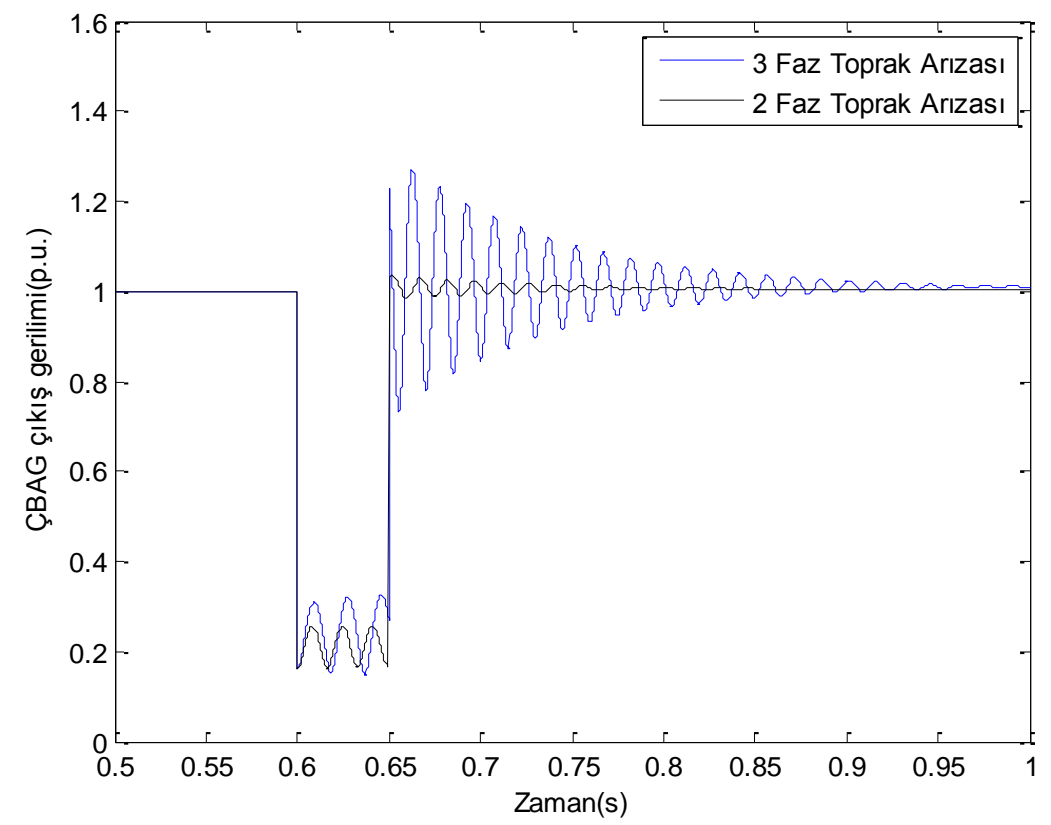

Şekil 10. 3 faz toprak ve 2 faz toprak arızasında ÇBAG çıkış gerilimi 


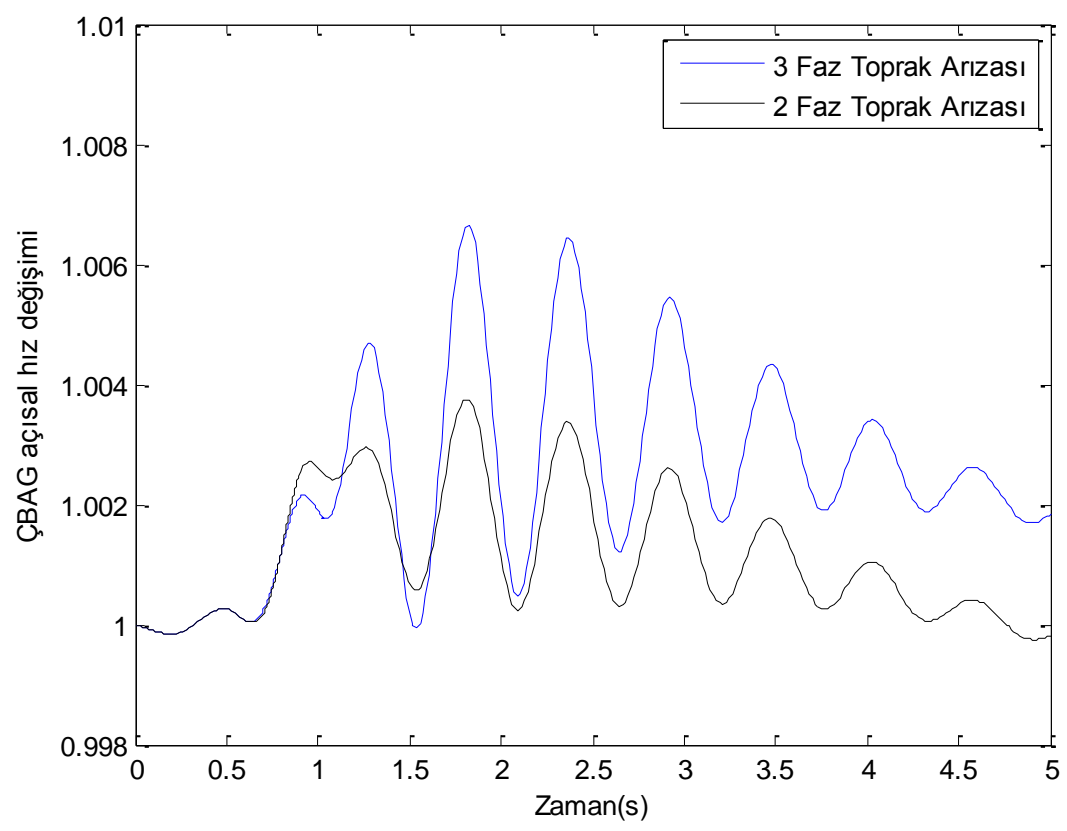

Şekil 11. 3 faz toprak ve 2 faz toprak arızasında ÇBAG açısal hız değişimi

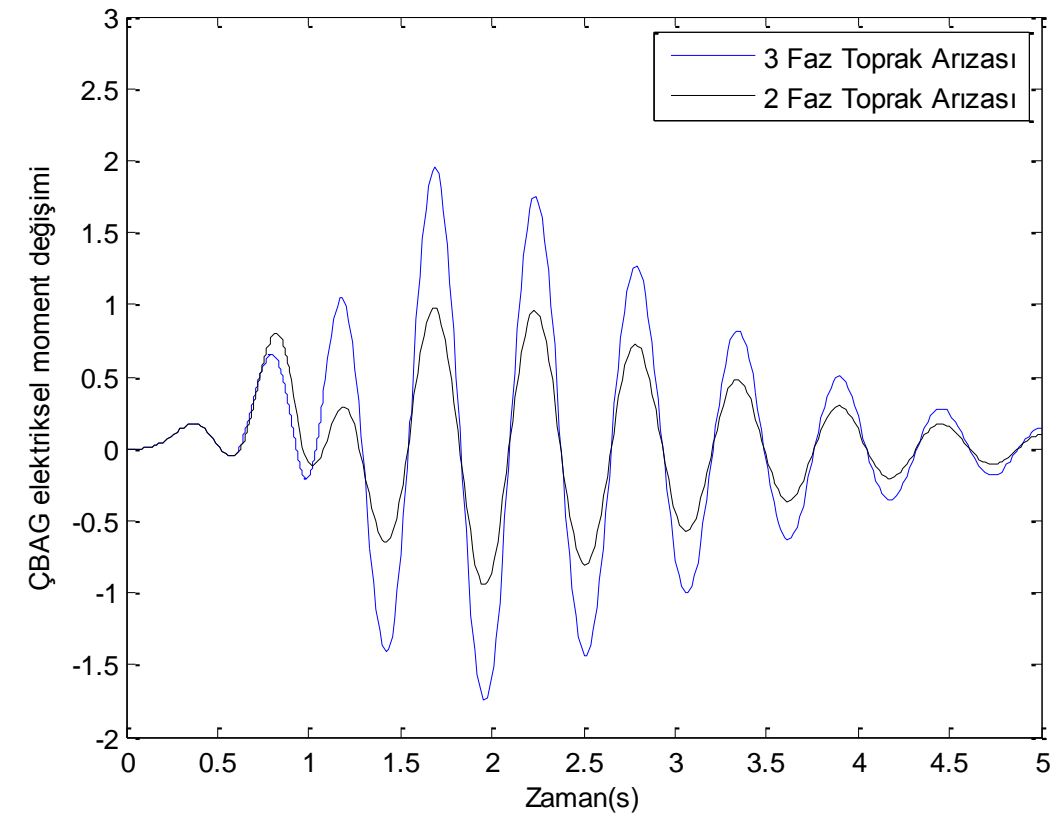

Şekil 12. 3 faz toprak ve 2 faz toprak arızasında ÇBAG elektriksel moment değișimi 


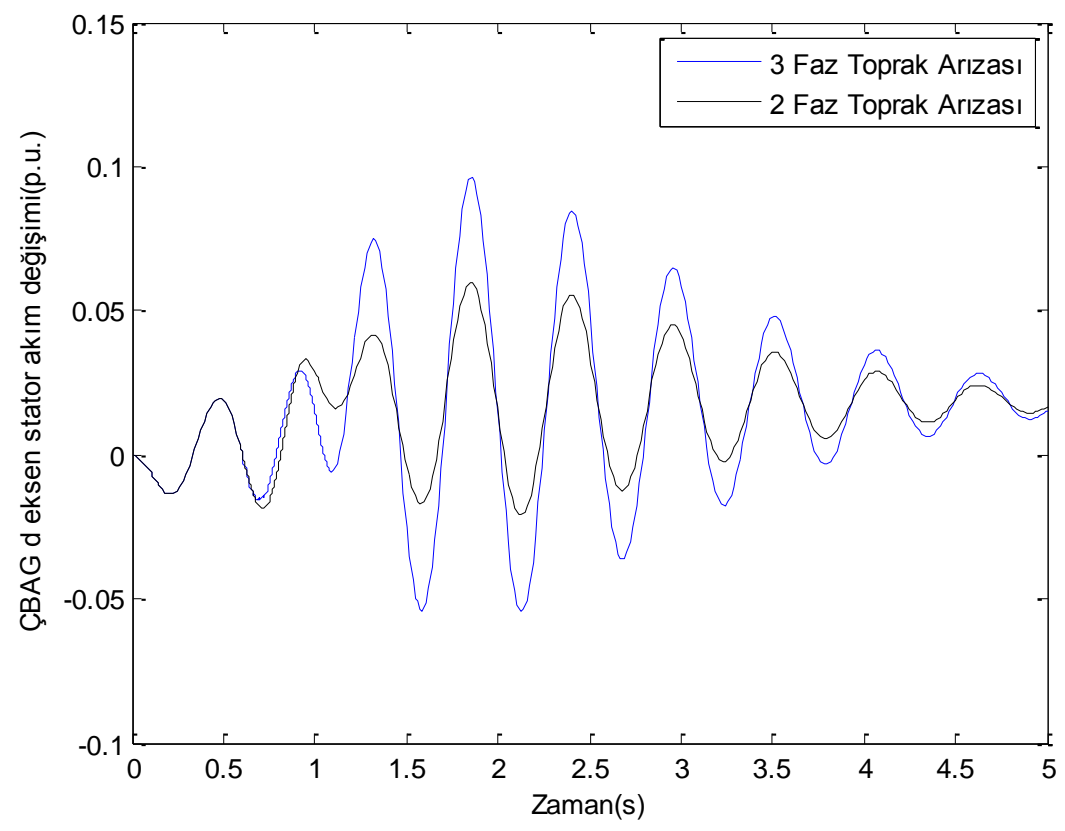

Şekil 13. 3 faz toprak ve 2 faz toprak arızasında ÇBAG d eksen stator akım değişimi

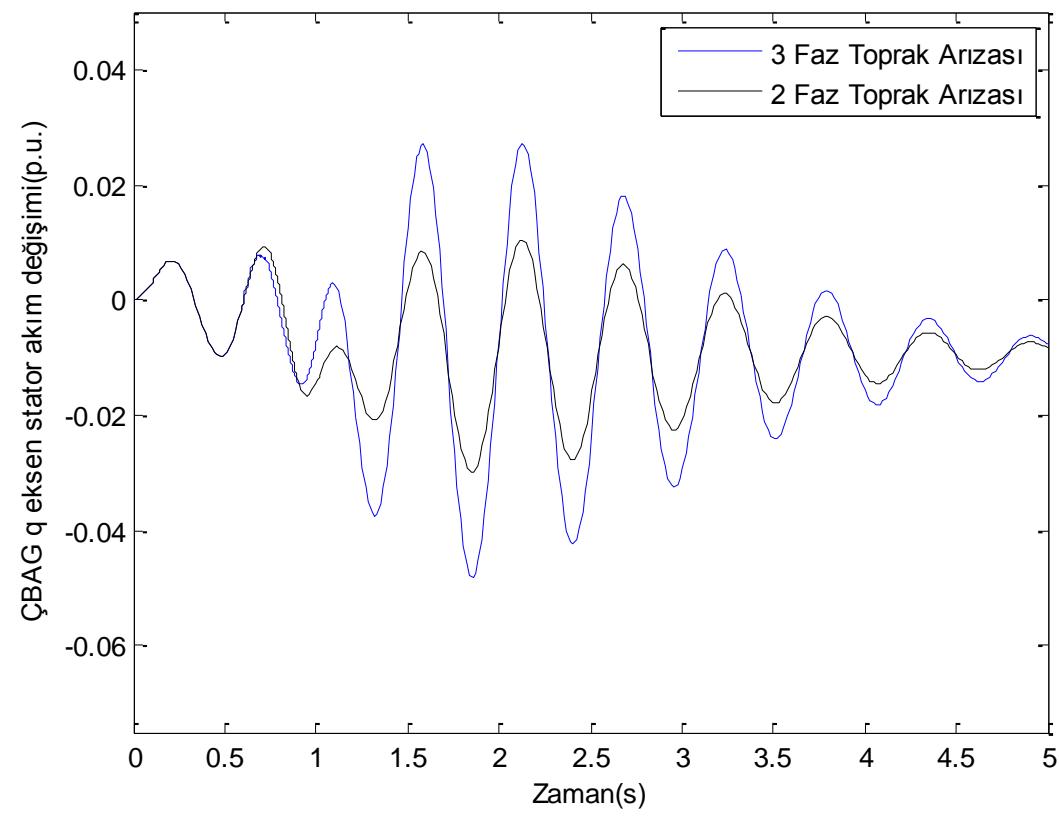

Şekil 14. 3 faz toprak ve 2 faz toprak arızasında ÇBAG q eksen stator akım değişimi

Şekil 9 ve Şekil 10 'da görülen $34 . \mathrm{kV}$ bara gerilimi ve ÇBAG çıkış gerilimde 3 faz toprak arızası esnasında sırasıyla yaklaşık olarak gerilim seviyeleri 0.55 ve 0.2 p.u civarına düşmektedir. 2 faz toprak arızasında ise gerilimler benzer şekilde yaklaşık 0.55 ve 0.2 p.u civarına düşmektedir. Şekil 11 'de görülen ÇBAG açısal hız değişiminde açısal hızın 3 faz toprak arızasında 1.0064 p.u. seviyelerine çıkarken, 2 faz toprak arızasında bu değer 1.0033 p.u. seviyesindedir. Şekil 12'deki elektriksel moment değişiminde hem 3 faz toprak arızasında hem de 2 faz toprak arızasında salınımların olduğu ve arıza sonrasında 5 saniye sonar kararlı hale geldikleri görülmektedir. Şekil 13 ve Şekil 14'deki statorun d-q eksen akımlarında ise salınımların oluştuğu ve yaklaşık olarak 5 saniyede sönümlendiği görüşmüştür. 


\section{SONUÇLAR}

Yapılan bu çalışmada, Türkiye'deki rüzgâr santrali gücü ve yükseltici transformatör güçlerinde imal edilen sistemin güç sistemine entegrasyonun sağlanması ile şebeke tarafında oluşabilecek simetrik ve asimetrik arızaların etkileri üzerinde durulmuştur. ÇBAG tabanlı rüzgâr santralinde DGİY için 0.05 olarak belirlenen arıza sürelerinde 3 faz, 3 faz toprak, 2 faz ve 2 faz toprak kısa devre etkileri incelenmiştir. $34.5 \mathrm{kV}$ 'luk baralarda meydana gelen arızalarda özelliklede 3 faz ve 3 faz toprak arizalarının bara gerilimleri ve ÇBAG açısal hız, elektriksel moment ve d-q eksen stator akımları üzerinde oldukça etkileri olmuştur. 3 faz ve 3 faz toprak arızalarında daha fazla salınımların oluştuğu ve daha geç sürede sistemin kararlı olduğu görülmüştür. Nispeten 2 faz ve 2 faz toprak arızlarında salınımların daha az olduğu ve sistemin daha kısa zaman içerisinde kararlı hale geldiği görülmüştür. $\mathrm{Bu}$ çalışma sayesinde üretimi yapılan DGIY için rüzgâr santral gücünün, yükseltici transformatör gücünün ve DGIYY durumlarının farklı benzetim çalışmaları analizlerinin yapılmasına zemin hazırlanmıştır.

\section{KAYNAKLAR}

[1] M. B. Salles, K. Hameyer, J. R. Cardoso, A. P. Grilo, C. Rahmann, "Crowbar system in doubly fed induction wind generators," Energies, vol. 3, no. 4, pp. 738-753, 2010.

[2] G. Pannell, D. J. Atkinson, B. Zahawi, "Minimum-Threshold Crowbar for a Fault-RideThrough Grid-Code-Compliant DFIG Wind Turbine," IEEE Transactions on Energy Conversion, vol. 25, no. 3, pp. 750-759, 2010.

[3] M. K. Döşoğlu, A. B. Arsoy, "Modeling and Simulation of Static Loads for Wind Power Applications," Neural Computing and Applications, vol. 25, no. 5, pp. 997-1006, 2014.

[4] M. K. Döşoğlu, A. B. Arsoy, "Rüzgar Santralinde Geçici Durumun İncelenmesi," Enerji Verimliliği Kongresi, Kocaeli, Türkiye, 2011, ss. 43-47.

[5] M. K. Döşoğlu, M. Dursun, "Investigation with ZIP load Model of Voltage Stability Analysis in Wind Turbine integrated Power System," 2018 2nd International Symposium on Multidisciplinary Studies and Innovative Technologies (ISMSIT), Ankara, Türkiye, 2018, ss. $1-5$.

[6] G. Xu, L. Zhu, Z. Pan, "Virtual Synchronous Control Using SOGI for Standalone DFIGBased Wind Turbines with Unbalanced and Nonlinear Loads," 21st International Conference on Electrical Machines and Systems (ICEMS) Jeju, South Korea, 2018, pp. 1133-1138.

[7] A. Mishra, P. M. Tripathi, K. Chatterjee, "A review of Harmonic Elimination Techniques in Grid Connected Doubly Fed İnduction Generator Based Wind Energy System," Renewable and Sustainable Energy Reviews, vol. 89, pp. 1-15, 2018. 
[8] M. Liu, W. Pan, R. Quan, H. Li, T. Liu, G. Yang, "A Short-Circuit Calculation Method for DFIG-Based Wind Farms,” IEEE Access, vol. 6, pp. 52793-52800, 2018.

[9] L. Holdsworth, I. Charalambous, J. B. Ekanayake, N. Jenkins, "Power System Fault Ride Through Capabilities of Induction Generator Based Wind Turbines," Wind Engineering, vol. 28, no. 4, pp. 399-409, 2004.

[10] L. R. Chang-Chien, C. M. Hung, Y. C. Yin, "Dynamic Reserve Allocation for System Contingency by DFIG Wind Farms," IEEE Transactions on Power Systems, vol. 23, no. 2, pp. 729-736, 2008.

[11] N. G. Khani, M. Abedi, G. B. Gharehpetian, G. H. Riahy, "Analyzing The Effect of Wind Farm to Improve Transmission Line Stability in Contingencies," Indian Journal of Science and Technology, vol. 8, no. 11, pp. 1-6, 2015.

[12] M. Mohseni, S. M. Islam, M. A. Masoum, "Impacts of Symmetrical and asymmetrical Voltage Sags on DFIG-Based Wind Turbines Considering Phase-Angle Jump, Voltage Recovery, and Sag Parameters," IEEE Transactions on Power Electronics, vol. 26, no. 5, pp. 1587-1598, 2011.

[13] S. Xiao, H. Geng, H. Zhou, G. Yang, "Analysis of the control limit for rotor-side converter of doubly fed induction generator-based wind energy conversion system under various voltage dips.” IET Renewable Power Generation, vol.7, no. 1, pp. 71-81, 2013.

[14] F. Wu, X. P. Zhang, K. Godfrey, P. Ju, "Small signal stability analysis and optimal control of a wind turbine with doubly fed induction generator," IET Generation Transmission and Distribution, vol. 1, no. 5, pp. 751-760, 2007.

[15] P. C. Krause, Analysis of Electric Machinery, 2th ed., New York, USA: McGraw-Hill, 2002.

[16] J. B. Ekanayake, L. Holdsworth, N. Jenkins, "Comparison of 5th Order and 3rd Order Machine Models for Double Fed Induction Generators (DFIG) Wind Turbines," Electric Power Systems Research, vol. 67, no. 3, pp. 207-215, 2003.

[17] J. G. Slootweg, H. Polinder, W. L. Kling, "Dynamic Modelling of A Wind Turbine with Doubly Fed Induction Generator," 2001 Power Engineering Society Summer Meeting, Canada, 2001. 